\title{
Gp100-Reactive Autologous Tumor Infiltrating Lymphocyte
}

National Cancer Institute

\section{Source}

National Cancer Institute. gp100-Reactive Autologous Tumor Infiltrating Lymphocyte. NCI Thesaurus. Code C38125.

Tumor infiltrating lymphocytes (TIL) isolated from a patient, exposed to the tumorassociated antigen gp100 in vitro, and then transferred back to the same patient to target tumor cells expressing gp100. gp100 human antigen is a wild-type self-antigen expressed by melanocytes, pigmented retinal cells and most melanomas. (NCI04) 